\title{
Influencias de Weininger en la concepción wittgensteiniana del judaísmo
}

\section{(Weininger's Influences in Wittgenstein's Conception of Judaism)}

\author{
Noemí Calabuig Cañestro
}

Recibido: 30 de septiembre de 2014

Aceptado: 23 de abril de 2015

\section{Resumen}

El objetivo de este trabajo es contribuir a dilucidar la concepción wittgensteiniana del judaísmo. En general se admite que la obra de Otto Weininger influyó en el pensamiento de Wittgenstein, pero no hay acuerdo sobre el contenido de esa influencia. Aquí sostenemos que esta es perceptible, no solo en la concepción wittgensteiniana de la ética, la genialidad, el talento, etc., sino también en su caracterización del judaísmo y en el uso que el filósofo hace de esta idea.

Palabras clave: judaísmo, genio, cultura, civilización, ética, religión, Weininger and Wittgenstein.

\begin{abstract}
The aim of this work is to contribute to elucidate Wittgenstein's conception of Judaism. It is generally acknowledged that Otto Weininger's work influenced the thought of Wittgenstein, but there is no agreement on the content of that influence. Here we argue that it is perceptible not only in the wittgensteinian conception of ethics, geniality, talent, etc., but also in his characterization of Judaism and the way the philosopher uses this idea.
\end{abstract}

Keywords: Judaism, genius, culture, civilization, ethics, religion, Weininger and Wittgenstein. 


\section{Introducción}

Uno de los filósofos que influyeron en la formación del pensamiento de Wittgenstein fue sin duda el vienés Otto Weininger ${ }^{1}$. Algunos conceptos fundamentales de su filosofía, como genio, carácter, talento, judaísmo, cultura, civilización, etc., desempeñaron un papel fundamental en el proceso de constitución de la filosofía de Wittgenstein ${ }^{2}$. Más aún, Wittgenstein compartía con Weininger algunos puntos de vista con respecto a las cuestiones que él consideraba más importantes: la concepción de la ética, de la lógica, de la relación que existe entre ambas, y como consecuencia, también del sujeto filosófico ${ }^{3}$. En 1931 Wittgenstein reconoce explícitamente que Weininger influyó sobre su pensamiento 4 .

Aquí vamos a abordar el problema del judaísmo. Prácticamente todas las reflexiones wittgensteinianas sobre este tema fueron escritas entre 1931 y 1940 (la mayoría durante el primer año) y están recogidas en Aforismos. Cultura y valor. Nuestro propósito no es ofrecer la interpretación definitiva de estos fragmentos, pero sí ayudar a quienes pretendan desentrañarlos, aportando para ello uno de los elementos fundamentales (aunque no el único) en la formación de sus opiniones al respecto: el elemento weiningeriano.

Para ello se exponen las tesis de Weininger sobre el espíritu judío, destacando algunas conexiones con el pensamiento de Wittgenstein, y se muestra que si se leen bajo el prisma weiningeriano, muchas de las observaciones de Wittgenstein sobre el judaísmo adquieren un sentido diferente al que tendrían consideradas aisladamente, un sentido que además es coherente con otras observaciones suyas (sobre la ciencia, el arte, la religión, etc.) y con su obra filosófica.

Esto no significa que Wittgenstein suscribiera íntegramente la teoría weiningeriana sobre el espíritu judío. De hecho, en algunos de sus aforismos parece establecer una especie de diálogo con su compatriota en el que revela unas veces su acuerdo y otras su distanciamiento. Además, no debe pasarse por alto la enigmática carta

\footnotetext{
1 En Janik (2004) y (1985), en McGuinness (1991), en Monk (2002), etc., se recogen evidencias a favor de esta tesis. Para conocer la vida y obra de Otto Weininger consultar Abrahamsen (1946) y Dallago (1912).

2 Para más información sobre ese tema ver Calabuig (2007a) y Calabuig (2010a).

3 Ver Calabuig (2010b).

4 “... Creo que hay una verdad si pienso que, de hecho, mi pensamiento es solo reproductivo. Creo que nunca he descubierto un movimiento intelectual, siempre me fue dado por algún otro. Lo único que he hecho es apresarlo apasionadamente de inmediato para mi labor de aclaración. Así, han influido sobre mí Boltzman, Hertz, Schopenhauer, Frege, Russell, Kraus, Loos, Weininger, Spengler, Sraffa. ¿Podrían ponerse como ejemplos de capacidad judía Breuer y Freud? Lo que descubro son nuevas metáforas. Cuando en su momento modelé la cabeza para Drobil, el acicate fue esencialmente obra de Drobil y en verdad mi trabajo fue de nuevo aclarar. Creo que lo esencial es llevar a cabo animosamente la actividad de aclarar; si falta este ánimo se convierte en un mero juego inteligente..." (Wittgenstein 2003, p. 58).
} 
dirigida a Moore el 23 de Agosto de 1931 en la que Wittgenstein afirma que añadiendo un "no" al conjunto del libro de Weininger5 se obtiene una verdad importante 6 , pues si el "no" ha de aplicarse al conjunto del libro, en alguna medida debe afectar a sus tesis sobre el judaísmo. Por todo ello, si conocer el pensamiento de Weininger permite comprender mejor a Wittgenstein, no es sólo ni principalmente por lo que les une, sino, en la misma medida, también por lo que les separa.

\section{La importancia de la cuestión judía}

Para empezar, debe considerarse qué es lo que Weininger entiende por judaísmo. Él mismo declara que cuando habla del judaísmo no se está refiriendo a una raza ni a un pueblo, tampoco a un credo oficialmente reconocido, ni a una escritura, sino a una tendencia del espiritu. Se trata, por tanto, de una constitución psíquica que es una posibilidad para todos los hombres, pero que ha encontrado en el judaísmo, históricamente considerado, su realización más grandiosa. Más adelante explicaremos en qué consiste.

Partiendo de este supuesto, Weininger se propone dilucidar la importancia y significado que tiene para la humanidad la idea platónica del judaísmo, así como la cualidad psíquica del judío típico en tanto que participa de esa idea. Esta investigación es para él de la máxima importancia, pues el problema del judaísmo atravesaría todos los ámbitos de la vida humana (el cultural, el religioso, el político, el artístico, el científico, el biológico, el histórico, el caracterológico y el filosófico), y el objetivo de su filosofía es precisamente desentrañar el significado de la idea de humanidad.

Este planteamiento de Weinigner puede aclararnos algo sobre el modo que tiene Wittgenstein de usar el adjetivo "judío" en sus observaciones: cierto tipo de música, determinada forma de hacer teatro, la concepción predominante de la ciencia, etc., serán caracterizadas como judías. La tragedia, por ejemplo, es considerada por Wittgenstein como algo no judío y Mendelssohn como el compositor menos trágico, de lo que se deduce que su música era judía ${ }^{7}$. El teatro de máscaras expresaría para Wittgenstein cierto carácter espiritual por el que solo se sienten atraídos los judíos, por eso cuando dice que las obras teatrales de Kraus deberían representarse con máscaras, estaría atribuyéndoles ese carácter8.

\footnotetext{
5 Se refería a Sexo y carácter.

${ }^{6}$ La carta se encuentra en Wittgenstein (1997b), p. 149. Para Szabados el error que Wittgenstein atribuye a Weininger sería metodológico y consistiría en convertir los prototipos construidos heurísticamente en esencias platónicas a las que los individuos deberían ajustarse (Szabados 2004, p. 35). En Calabuig (2010b), se exponen otras posibles interpretaciones de esta.

7 Wittgenstein (2003), p. 33.

8 Wittgenstein (2003), p. 48.
} 
Asimismo, Weininger está convencido de que en su época se puede catalogar psicológicamente a los hombres civilizados dependiendo de la posición que adopten frente al judaísmo. De este modo, los arios más puros, aquellos que tienen la certeza de serlo, no serían antisemitas, mientras que en los antisemitas más agresivos se encontrarían siempre cualidades judías, aunque en su sangre no haya rastro de mezcla semita. Así, por ejemplo, si Zola era filosemita, ello se debía precisamente a que estaba libre de influencia judía. Por otro lado, el hecho de que muchos genios hayan sido antisemitas se explicaría por la existencia en su espíritu de múltiples personalidades, incluida la judía, lo que les proporcionaría una mayor capacidad para comprenderla.

Por norma general, dice el filósofo, los antisemitas más enérgicos son a su vez semitas, aunque no puros, y dirigen sus críticas fundamentalmente contra sus compañeros, sin haberse formado antes un juicio sobre ellos mismos. Sólo los judíos y los arios puros (se entiende que psicológicamente) no son en absoluto antisemitas.

Estas afirmaciones deben entenderse teniendo como trasfondo una teoría psicológica desarrollada por Weininger según la cual el amor y el odio son fenómenos de proyección: ciertas cualidades psíquicas o espirituales que se encuentran en nosotros mismos las proyectamos sobre un cuerpo extraño, convirtiéndolo así en el objeto de nuestra pasión. Por eso puede decirse que odiamos únicamente aquello que nos desagrada de nosotros mismos y amamos lo que de nosotros nos agrada. Este gesto supone al mismo tiempo un autoengaño, una falta moral. Debe tenerse en cuenta que para Weininger la honestidad es el objetivo último de la moral y la característica por excelencia del hombre genial, que también se caracteriza por su originalidad.

De modo que Weininger era consciente de que su animadversión hacia el espíritu judío podía explicarse por la existencia en su propia personalidad de rasgos judíos. De hecho, los acontecimientos que precedieron a su suicidio confirman que se consideraba a sí mismo - probablemente por su incapacidad para reconocer y aceptar su propio judaísmo- un criminal.

Algunas observaciones de Wittgenstein ponen de manifiesto que también le preocupaba especialmente la falta de honestidad; que era consciente de la dificultad que supone conocerse a uno mismo y no engañarse; y que vencer esa dificultad era para él la clave de la originalidad.

Nada es tan difícil como no engañarse (Wittgenstein 2003, p. 80).

Me inclino fuertemente a decir la mentira (Wittgenstein 2003, p. 86).

Es difícil entenderse bien a uno mismo, pues lo que se podría hacer por magnanimidad y bondad, puede hacerse también por cobardía o indiferencia (Wittgenstein 2003, p. 98). Cuando alguien no miente es suficientemente original. Pues la originalidad que sería de desear no puede ser un artificio o una propiedad, como se dice siempre. 
Sí, es un principio de buena originalidad el no querer ser lo que uno no es. Y todo esto ya ha sido dicho mucho mejor por otros (Wittgenstein 2003, p. 116).

Nunca es grande quien se desconoce a sí mismo: quien se engaña (Wittgenstein 2003, p. 101).

Sabemos que Wittgenstein también estuvo cerca del suicidio y que en su juventud quiso ocultar su origen judío para ser admitido en una club. Pero lo más significativo es que se esfuerza por detectar qué hay de judío en su manera de pensar y de trabajar 9 . Por ejemplo, en 1930 escribe:

En este mundo (el mío) no hay una tragedia y por ello tampoco existe todo lo infinito que hace surgir precisamente la tragedia (como resultado).

Por así decirlo, todo es soluble en el éter universal; no hay durezas.

Es decir, la dureza y el conflicto no se convierten en algo sublime, sino en una falta (Wittgenstein 2003, p. 44).

En este párrafo Wittgenstein estaría caracterizando su propio mundo, su manera de pensar y de vivir, como judía, puesto que un año antes afirma:

La tragedia consiste en que el árbol no se dobla, sino que se rompe. La tragedia es algo no judío (Wittgenstein 2003, p. 32).

Del planteamiento de Weinigner - según el cual hay arios antisemitas y, por tanto, con rasgos judíos en su personalidad - se deriva que existe realmente una diferencia entre los judíos como individuos, pertenecientes a una raza o a un pueblo, y el judaísmo (como inclinación espiritual) y que, en consecuencia, ambos conceptos pueden y deben considerarse por separado:

Existen arios que son más judíos que algunos judíos, y existen judíos que en realidad son más arios que ciertos arios (Weininger 2004, p. 474).

Entre los individuos del primer tipo se hallaría, por ejemplo, el escritor y filósofo Friedrich Schiller. Weininger lo critica en Sobre las últimas cosas por su incapacidad para comprender la tragedia, su entusiasmo civilizatorio (que juzga infundado y ofensivo) y su perniciosa identificación de la cultura con la civilización, rasgos que considera característicos del judío típico.

Como vemos, la idea de que la tragedia es algo no judío ya se encontraba en Weininger. Otra concomitancia entre los dos autores sería el esfuerzo por hacer explícita la diferencia entre la cultura y la civilización ${ }^{10}$ y por mostrar su falta de

\footnotetext{
9 Wittgenstein (2003), pp. 57, 58 y 59.

10 “Quizá surja alguna vez una cultura de esta civilización.” (Wittgenstein 2003, p.122).
} 
sintonía con la segunda, a la que consideran que va unida, como su esencia, la idea de progreso11. Además, aunque podría tratarse de una mera coincidencia, Wittgenstein también cuestiona el valor de la obra de Schiller ${ }^{12}$.

Tampoco Wagner, al que Weininger considera el "artista más grande de la humanidad", estaría para él libre de judaísmo. Prueba de ello serían tanto la hostilidad que mostraba contra las grandes óperas y el teatro, hacia las que en el fondo se sentía muy atraído (como se aprecia en Lohengrin), como la pesadez y exceso de sonoridad de algunos de sus pasajes musicales; en definitiva, su debilidad por lo accesorio, por la apariencia.

Wittgenstein también deja claro su rechazo de lo accesorio en el arte - por ejemplo, en arquitectura ${ }^{13}-\mathrm{y}$, de acuerdo con su ideal estoico, en la vida misma. Esa es la razón por la que atribuía a algunos pasajes de Wagner un exceso de destreza, lo que siempre es sintomático de falta de inspiración o de genio14.

Por otro lado, para Weinigner participar del judaísmo en cierta medida no criminaliza automáticamente; todo depende del empeño que uno ponga en identificar, comprender y superar la propia inclinación. Por eso dice que a Wagner:

El judaísmo le sirvió de mucho para llegar al completo esclarecimiento y afirmación del polo opuesto, para elevarse hasta Siegfried ${ }^{15}$ y Parsifall $^{16}$, y para dar al germanismo la máxima expresión que ha encontrado en la historia (Weininger 2004, p. 475).

Ahora bien, casos como éstos son excepcionales, de lo contrario no tendría sentido la radical oposición y caracterización del tipo judío frente al ario, como tampoco se entendería la preferencia de Weininger por unos términos que en el lenguaje ordinario designan razas o pueblos.

No obstante, considerar las excepciones es imprescindible para entender la perspectiva weiningeriana, es decir, para tener claro que no nos encontramos ante una investigación innatista - pues la identificación del judío no se basa en rasgos físicos o en el tipo de sangre, sino en el grado de proximidad a un arquetipo psicológico o espiritual construido heurísticamente $-\mathrm{y}$ tampoco determinista, pues ser o no ser judío dependerá en última instancia de la libertad de la voluntad.

\footnotetext{
11 Wittgenstein (2003), pp. 38-40.

12 Wittgenstein (2003), p. 124.

13 Sobre esta cuestión ver Calabuig (2007b).

14 Wittgenstein (2003), pp. 90 y 94.

15 De esta obra dice Weininger que es "lo menos judío que pueda imaginarse" (Weininger 2004, p. 474).

16 Que, según Weininger, "siempre será tan incomprensible para los judíos genuinos" (Weininger 2004, p. 475). El padre de Weininger, que era judío, había confesado su incapacidad para comprender esa pieza.
} 


\section{El Judío y la Mujer}

En Sexo y carácter, la única obra que Weininger publicó, el problema de la mujer ocupa el lugar central. El objetivo general de esta obra es analizar las diferencias entre lo masculino y lo femenino desde todas las perspectivas (biológica, psicológica, cultural, metafísica, etc.) y basar en ese análisis su crítica a la civilización moderna ${ }^{17}$. En este contexto, el Hombre y la Mujer funcionan como tipos ideales para analizar la realidad empírica, donde los individuos siempre se aproximan más a uno de estos dos polos estructurales, sin llegar nunca a ser absolutamente masculinos o femeninos.

Mientras el Hombre representa la acción, la conciencia, la creación, la fuerza de voluntad, la libertad y el ser, la Mujer representa la materia pasiva, la inconsciencia, la reproducción, la indolencia, la necesidad y, en definitiva, la nada.

Partiendo del supuesto biológico de la bisexualidad universal18, Weininger considera hombres a los individuos de la especie humana que participan psicológicamente de la idea de Hombre en más de un cincuenta por cien, siendo el resto de individuos mujeres.

De hecho, dice, existen ciertos pueblos y razas donde los individuos que anatómicamente son considerados hombres se aproximan muy poco o sólo en raras ocasiones a la idea de masculinidad, que también coincide con la de genialidad. Este es el caso de los judíos. Veamos dónde radica para Weininger su parentesco con la feminidad.

\section{El yo inteligible}

Igual que la Mujer, dice Weininger, el Judío carece de comprensión y necesidad de la propiedad, especialmente de la propiedad de la tierra, y ello a pesar de su habilidad comercial. El concepto de propiedad sólo es comprensible desde la individualidad de un sujeto con límites bien diferenciados, pero el judaísmo se caracteriza psicológicamente por la falta de determinación interior:

Al no creer en nada se refugia en lo material, solo a esto se debe su ansia por el dinero. En él busca una realidad y pretende que el "negocio" le convenza de que la existencia tiene un fin. El único verdadero valor que reconoce es, pues, el dinero "ganado". Y, sin embargo, no es ni siquiera un verdadero hombre de negocios (Weininger 2004, p. 506).

\footnotetext{
17 Para un análisis completo de Sexo y carácter ver Sengoopta (2000).

18 Weininger (2004), p. 34.
} 
El siguiente fragmento de 1931 podría ser una respuesta de Wittgenstein a las anteriores consideraciones weiningerianas:

Poder y propiedad no son lo mismo. Aun cuando la propiedad nos dé poder. Cuando se dice que los judíos no tenían sentido de la propiedad, esto puede unirse al hecho de que les gusta ser ricos, pues para ellos el dinero es una determinada forma de poder, no de propiedad. (Por ejemplo, yo no quisiera que mis gentes se volvieran pobres, pues deseo para ellas un cierto poder. Aunque, también, que puedan utilizar bien este poder.) (Wittgenstein 2003, p. 60).

Como puede deducirse de esta observación, Wittgenstein estaría de acuerdo con Weininger en separar nítidamente el dinero de la propiedad y atribuir a los judíos el gusto por lo primero. Pero añade que es el poder que da el dinero lo que verdaderamente atrae a los judíos hacia este. Es decir, que su deseo de ser ricos revela una tendencia más profunda: su voluntad de poder.

Wittgenstein reconoce que él mismo ve el dinero como una forma de poder y que, precisamente por eso, desea que "su gente" (probablemente se refiera a su familia) no se haga pobre. Pero, por otro lado, el filósofo parece estar distanciándose de la valoración negativa que suele hacerse - y que el mismo Weininger hace ${ }^{19}$ - del deseo de poder, pues sugiere que el poder también puede desearse, no como un fin en sí mismo, sino como un medio al servicio de fines buenos.

Según Weininger, en sintonía con su incomprensión de la propiedad, a los judíos les resulta totalmente ajeno tanto el socialismo como la idea de Estado, no obstante tienden a la comunidad y al comunismo. Mientras el socialismo es ario (Owen, Carlyle, Ruskin, Fichte), porque presupone la humanidad en cada uno de los miembros de la sociedad y valora el esfuerzo por la cooperación, el comunismo es judío, porque tiene su base en el gregarismo, y tanto a los judíos como a las mujeres les place reunirse ${ }^{20}$.

La idea de Estado que Weininger tiene en mente es la que se encuentra en el Contrato Social de Rousseau, que consiste en la decisión voluntaria de obedecer a un orden jurídico determinado, decisión que sólo puede ser tomada por individualidades éticas.

El sionismo, por tanto, significa la negación del judaísmo, a cuya idea es inherente la colonización de la Tierra. Pero la razón de todo ello es que, igual que a la mujer, al judío le falta personalidad y conciencia de sí, carece de yo inteligible y no tiene valor propio. El yo inteligible, que se opone al sujeto empírico, es el sujeto de

19 En Sobre las últimas cosas, Weininger considera inmoral la postura de quien persigue el conocimiento no por sí mismo, sino por el poder que éste conlleva. Wittgenstein podría contestarle que el poder que da el conocimiento también puede desearse como medio para fines buenos y que no habría nada inmoral en ello.

20 Weininger (2004), p. 478. 
la lógica y la ética, lo valioso en el hombre, la voluntad. Es, además, el ideal al que se aproxima el hombre genial. Sobre este sujeto, Weininger dice:

Mi propia existencia, el "yo", si es que tienen valor, no pueden ser probados; y del mismo modo el "tú", si no es consecuencia de una razón y no puede ser usado como medio para un fin, no puede ser demostrado. La refutación del solipsismo no sería en absoluto compatible con la ética, como tampoco lo sería la posibilidad de probar la existencia del propio yo. (Weininger 2008, p. 192).

En sus Diarios filosóficos Wittgenstein también admite la existencia de este sujeto:

De no existir la voluntad, no habría tampoco ese centro del mundo que llamamos el yo, y que es el portador de la ética.

En lo esencial, bueno y malo, es sólo el yo, no el mundo.

El yo, el yo es lo más profundamente misterioso.

El yo no es un objeto.

Estoy objetivamente frente a todo objeto. No frente al yo. (Wittgenstein 1982, p. 136).

Y en el Tractatus, cuando habla del yo filosófico, del sujeto metafísico, e incluso de la voluntad como soporte de la ética, parece referirse a ese mismo sujeto. Pues, aunque no forma parte del mundo, de él depende todo lo valioso que pueda hallarse en el mundo, todo lo bueno y lo malo21.

Además, como muestra en algunos de sus aforismos, el valor de lo que un hombre expresa, su genialidad, también estaría en función de ese sujeto o de la voluntad. Por ejemplo:

La grandeza de lo que alguien escribe depende de todo lo demás que escriba y haga (Wittgenstein 2003, p. 124).

Pues bien, según Weinigner, sería precisamente la ausencia de sujeto inteligible (o de voluntad) en el individuo judío lo que explicaría su falta de respeto hacia su propia persona y hacia la de los demás. Ello se manifestaría en la forma de una gran insociabilidad y la tendencia a adquirir el propio valor rebajando a los otros.

Puesto que no se valora, el judío también carece de orgullo y respeto hacia sus antepasados. Eso explicaría que el peso que se otorga a la tradición judía no sea en el fondo otra cosa que el peso de su esperanza en el futuro. De hecho, concluye Weininger, la historia de los judíos podría resumirse en un solo acontecimiento: el paso a través del Mar Rojo, que culmina con el agradecimiento de los cobardes fugitivos a su valeroso salvador.

21 Wittgenstein (1973), pp. 145 y 179. 


\section{Respeto}

Wittgenstein piensa que el judaísmo es considerado generalmente como una anomalía en la historia de los pueblos de occidente, pero que Weinigner no es víctima de ese error. Para comprender qué significa esto, analizaremos el siguiente fragmento:

¡Considera esta tumefacción como miembro auténtico de tu cuerpo! ¿Puede hacerse así, por mandato? ¿Está en mi poder el tener arbitrariamente un ideal de mi cuerpo o no? Por ello la historia de los judíos no se trata en la historia de los pueblos europeos con la extensión que de hecho merece por su influencia en los acontecimientos europeos, pues se la considera una especie de enfermedad y anomalía de la historia, y nadie pone con gusto, al mismo nivel, una enfermedad y la vida normal [y nadie habla con gusto de una enfermedad como algo paritario a los procesos sanos (aun los dolorosos) del cuerpo]. Puede decirse: esta tumefacción puede ser considerada como parte del cuerpo cuando se modifica todo el sentimiento del cuerpo (cuando se modifica todo el sentimiento nacionalista por el cuerpo). De no ser así, como mucho se la puede soportar.

Es posible esperar que un individuo soporte o menosprecie tales cosas; pero no se puede esperar esto de una nación, que precisamente es nación por no menospreciarlas. Es decir, es una contradicción esperar que alguien conserve su antiguo sentimiento estético por el cuerpo y dé la bienvenida a la tumefacción. (Wittgenstein 2003, p. 60).

Ray Monk reconoce la influencia de Weininger y de Spengler en esta observación de Wittgenstein, aunque no profundiza en el carácter de esa influencia. Según Monk, lo que subyace a esta observación es una concepción racial de lo judio: esta metáfora orgánica que compara la historia judía con un tumor en la historia de los pueblos de occidente parece sugerir, dice, que aquellos que pretendan expulsar el "bacilo nocivo" de su entorno están en su derecho. $\mathrm{O}$ al menos que no puede esperarse que, como nación, hagan otra cosa. En ese sentido, la asimilación del judío sería para Wittgenstein como la propagación de una peligrosa enfermedad que podría acabar con la, de otro modo, saludable nación aria.

Monk continúa diciendo que afortunadamente, y aunque lo que resuena en estos comentarios de Wittgenstein es un antisemitismo racial más propio del Mein Kampf, incluso, que de Weininger, no se encuentra ninguna afinidad esencial entre este y los nazis, a los que él mismo describe como un bárbaro "grupo de gánsters".

Y concluye su interpretación señalando que las observaciones de Wittgenstein en torno al judaísmo eran fundamentalmente introspectivas y que utiliza el lenguaje del antisemitismo, bastante corriente en su contexto intelectual, como una metáfora para sí mismo que expresa su deseo de encontrar un nuevo principio para su vida $^{22}$.

22 Ver Monk (2002), pp. 292-97. 
Creemos que la conclusión de Monk no es incorrecta. Es cierto que estas observaciones manifiestan la lucha interior en la que se hallaba inmerso Wittgenstein. De hecho, creemos que deben considerarse como formando parte de esa labor de clarificación y de trabajo sobre uno mismo que significa para él la terea filosófica ${ }^{23}$. Pero por eso mismo pensamos que Wittgenstein también está intentando honestamente comprender el fenómeno del antisemitismo y que, a diferencia de lo que opina Monk, no está defendiendo la superioridad de la raza aria frente a la judía; y tampoco la de la nación aria o la cultura europea.

Fijémonos, en primer lugar, en que Wittgenstein está señalando lo que considera un error frecuente: considerar el judaísmo como una anomalía o una enfermedad dentro de la historia de occidente. Ese error implicaría otros dos errores: en primer lugar, menospreciar la importancia de la influencia del judaísmo en los acontecimientos europeos y, en segundo lugar, impedir una interpretación del judaísmo que facilite la comprensión, el respeto y la convivencia pacífica.

Para Wittgenstein la actitud epistemológica que promueve el respeto es la que reconoce la imposibilidad de justificar la superioridad de una ética sobre las otras 24 . Pero precisamente por eso, porque por debajo de cualquier ética no hay nada, porque ese es el más profundo terreno sobre el que levantamos nuestras voces y justificamos nuestras acciones, cuando dos actitudes éticas diferentes se enfrentan, no hay solución o acuerdo racional posible.

En ese sentido, la alusión de Wittgenstein a la percepción estética del cuerpo apunta a que entiende que el ámbito de la política - y por tanto también el de los sentimientos nacionalistas - responde fundamentalmente a criterios estéticos, y no racionales. En este terreno la fundamentación racional resultaría imposible 25 .

Por todo ello, lo que Wittgenstein parece señalar en la cita de arriba es la radical incomprensión entre la cultura occidental y la judía y la imposibilidad de una conciliación. Su diagnóstico es, en ese sentido, pesimista: el final del enfrentamiento solo podría venir marcado por la disolución de una de las dos culturas, por la pérdida de su identidad nacional o, dicho de otro modo, por un cambio radical en sus actitudes ético-religiosas y estéticas. Y este cambio, tal y como sugiere la primera parte del párrafo de Wittgenstein, nunca es producto de una imposición externa, pues no se puede forzar la voluntad. Requeriría la aceptación voluntaria y conscien-

\footnotetext{
23 "El trabajo filosófico - como en muchos aspectos sucede en la arquitectura - consiste, fundamentalmente, en trabajar sobre uno mismo. En la propia comprensión. En la manera de ver las cosas (Y en lo que uno exige de ellas.)" (Wittgenstein 2003, p. 54).

24 Esta es la concepción de la ética que se desprende de la Conferencia sobre ética, de los apuntes de Rush Rhees y de las notas que Friedrich Waismann tomó sobre sus conversaciones con Wittgenstein. Todo ello está publicado en Wittgenstein 1989.

25 En los Aforismos, refiriéndose a nuestros juicios morales, Wittgenstein se expresa así: "Lo inefable (aquello que me parece misterioso y que no me atrevo a expresar) proporciona quizá el trasfondo sobre el cual adquiere significado lo que yo pudiera expresar." (Wittgenstein 2003, p. 45).
} 
te de la nueva perspectiva por parte de cada individuo. De modo que en este terreno, en el que ni la imposición ni las justificaciones surten efecto, sólo queda el recurso a la persuasión, que no siempre es efectiva.

Coincidiendo con Wittgenstein, Weininger sostiene que la única solución al problema del judaísmo radica en la desaparición de una de las dos culturas; y que ello no se consigue ni mediante la fuerza ni a través de razones.

Pero aunque Weininger también coloca el respeto en el centro de la actitud ética, lo cierto es que defiende y justifica la existencia de una jerarquía entre las doctrinas éticas y religiosas. Esta estaría en función del grado de autonomía individual y, por ende, de respeto a la idea de humanidad, que promueven. En ese sentido, para Weininger la doctrina cristiana sería superior a la judía, porque transmite la idea de que Dios es lo divino en el hombre y que el ser humano puede convertirse en Dios, lo que promovería una actitud autónoma. La religión judía, al propiciar una imagen de Dios como fuerza externa, independiente de la propia voluntad, y a la que esta debe someterse, estaría fomentando una actitud heterónoma y servil.

Por eso está convencido de que es el judaísmo el que tiene que desaparecer. ¿Cómo? Mediante la decisión libre e inquebrantable por parte de cada individuo judío de renunciar al judaísmo. Renunciar al judaísmo significa valorar y respetar la idea de humanidad, adquiriendo así la máxima autoestima personal. Ello constituiría la única libertad posible26.

Pues bien, si la interpretación ofrecida es correcta, el siguiente fragmento sugiere que, a juicio de Wittgenstein, Weininger no estaría considerando el judaísmo como una anomalía en la historia de occidente, ni habría restado importancia a la influencia del judaísmo en los acontecimientos europeos:

En la civilización occidental, el judío es medido siempre con escalas que no le corresponden... y en la medida en que las palabras de nuestro (idioma) nos parezcan la medida general, siempre seremos injustos con ellos. Y así, unas veces son sobrevalorados y otras menospreciados. Correctamente, Spengler no pone a Weininger entre los filósofos (pensadores) occidentales (Wittgenstein 2003, p. 53).

\footnotetext{
26 Weininger (2004). p. 486. Pero, según Weininger, no se puede convencer a nadie de que se libere, como no se le puede convencer de que haga lo correcto: "No se puede probar que la gente debería hacer el bien. Pues si eso pudiera ser deducido, la idea de lo bueno sería la consecuencia de una causa y entonces también podría ser el medio para un fin. Si el bien debe ser hecho, entonces el bien, para que se quisiera hacer por sí mismo, debería ser idéntico a eso que no puede ser en absoluto la consecuencia de una causa, lo que no puede ser en absoluto el medio para un fin.” (Weinigner 2008, p. 190). Para ello es necesario un acto de fe o participar de la gracia: "Aquel para el que no está claro como el día que lo bueno ha de ser elegido antes que lo malo, el que aquí no elige de forma absolutamente inequívoca, inquebrantable, el que no quiere mantenerse firme frente al diablo y duda si debería mantenerse firme ante él, ese no es partícipe de una cosa: la gracia." (Weinigner 2008, p. 191).
} 


\section{Disimulo}

Según Weininger, a veces se ha sostenido que los defectos de los judíos, como su habilidad para ocultarse, se deben a la brutal opresión y servidumbre a la que fueron sometidos durante toda la Edad Media y hasta el siglo XIX. El sentimiento de esclavitud que les caracteriza, por tanto, habría sido inculcado en el judío por el ario.

Pero para Weininger esta autoacusación de los cristianos, que a menudo sienten al judío como su propia culpa, carece de justificación, porque se fundamenta en un error: creer que las influencias exteriores pueden modificar el carácter de un individuo en lo esencial, sin que antes se encontrara también en su interior la posibilidad de tal modificación. Según Weininger, cualquier modificación en el carácter se dirige siempre desde el interior hacia el exterior. Por otra parte, sostiene, todavía no se ha demostrado que se hereden las cualidades adquiridas. Weininger se opone radicalmente a la tesis según la cual el carácter del hombre está determinado por el ambiente 27.

En 1931, Wittgenstein escribe:

Algunas veces se ha dicho que el disimulo y ocultación de los judíos han sido producidos por la larga persecución. De hecho esto es falso; en cambio es evidentemente cierto que sólo existen, a pesar de esta persecución, porque tienen inclinación a la ocultación. Como podría decirse que un animal no se ha extinguido porque tiene la posibilidad o capacidad de ocultarse. Con ello, en modo alguno quiero decir, desde luego, que haya de alabar por ello tal posibilidad. (Wittgenstein 2003, p. 62).

Aquí Wittgenstein parece estar de acuerdo con Weininger: los judíos tienen la habilidad de ocultarse; esta habilidad les ha permitido sobrevivir, pero no es una respuesta a la persecución que han padecido; y que sirva para favorecer la supervivencia no la convierte en algo loable.

A continuación, Wittgenstein emplaza su reflexión en el terreno de la biología y compara la habilidad para ocultarse de los judíos con la de cualquier otro animal. De este modo, nos estaría advirtiendo que interpretarla como consecuencia de la persecución histórica sería defender una especie de lamarkismo social. Pero si los judíos no hubieran tenido desde el principio la habilidad de esconderse, simplemente no hubieran sobrevivido.

No obstante, Wittgenstein quiere evitar una posible y bastante común mala interpretación del darwinismo, que ha heredado el darwinismo social, y que consiste en atribuir un valor absoluto a las cualidades que permiten la supervivencia $o$, dicho de otro modo, entender la supervivencia - ya se trate de un individuo, de una especie, o de una cultura particular - como un fin en sí mismo.

27 Ver Weininger (2004), p. 480. 
De hecho, creemos que considerar como criterio o medida para nuestros juicios de valor la supervivencia del individuo o de la especie sería adoptar una perspectiva utilitarista totalmente opuesta a la de Wittgenstein - y, por supuesto, a la de Weininger -. Por otro lado, tomar como criterio de valor una cultura particular, como, por ejemplo, la europea, iría en contra del relativismo cultural defendido por el filósofo; un relativismo que le lleva a afirmar, por ejemplo:

La desaparición de una cultura no significa la desaparición del valor humano, sino sólo la de algunos medios de expresión de este valor (Wittgenstein 2003, p. 39).

De todo esto se deduce igualmente que si posibilitar la supervivencia no es razón para alabar la habilidad de ocultación de los judíos, tampoco debería serlo para menospreciarla.

Finalmente, aunque la comparación biológica pueda llevar al lector a inferir que Wittgenstein considera esta habilidad de los judíos como algo innato y perteneciente a la raza, esta no sería la interpretación más coherente con sus otros aforismos y con lo expuesto anteriormente. Como hemos dicho, Wittgenstein se movería en la línea de Weininger: el judaísmo en el individuo sería una inclinación hacia determinadas actitudes, una tendencia psicológica o una manera de ver las cosas que este ha adquirido por participar en las costumbres propias de ese pueblo.

Pero ¿en qué se basa Wittgenstein para atribuir a los judíos la tendencia a ocultarse? Puede que la respuesta la proporcione Ranjit Chaterjee. La tesis central de su obra es que Wittgenstein era un pensador judío que ocultaba su verdadera identidad por razones intelectuales. Según Chaterjee, para entender la obra de Wittgenstein es fundamental analizar los rasgos de la tradición judía, que este conocía bien.

Chaterjee explica que la vida de la gente de Israel ha sido condicionada desde el principio por la separación, la revelación, el pacto, la escritura y el comentario, lo que ha generado (junto con otros motivos) una forma de vida intelectual diferente a la del contexto greco-cristiano de europeos no judíos y occidentales. Desde su nacimiento, como condición del pacto en Sinaí, Israel es obligada a estar separada de "las naciones". La palabra hebrea para la separación es kadosh o santo. Goy kadosh, la gente santa, es la gente separada, de manera que no se puede aspirar a la santidad sin estar separado. Esta separación se lleva a la práctica a través de una serie de directrices o mandatos (mitzvot). Generalmente se reconocen 613 mandatos que se dirigen a diferentes aspectos de la vida, como la ropa, la higiene, la oración, el sexo, el matrimonio, etc.. La obediencia a las normas limita o reprime el contacto con la gente no practicante, separa al judío del gentil y lo santifica como miembro de una nación sagrada. Y puesto que la religión judía, a diferencia del cristianismo o el islam, no es proselitista, no tiene la necesidad de explicarse ante el mundo exterior (Chaterjee 2005, pp. 48-56). 
Pues bien, si Chaterjee tiene razón, es probable que Wittgenstein se refiriera a este hecho cuando hablaba de la habilidad de los judíos para ocultarse. Pero además se estaría refiriendo a sí mismo, a su propio judaísmo y a su esfuerzo por ocultar este hecho. Aunque, por supuesto, lo estaría haciendo disimuladamente 28.

\section{Falta de fe y materialismo}

Según Weinigner, el judío carece de fe, su monoteísmo es una superstición fundada en un sórdido temor, por lo que no tiene nada que ver con la verdadera creencia en Dios; es más bien su negación ${ }^{29}$.

Lo cierto es que Wittgenstein también distingue claramente la fe de la superstición y considera que la segunda está fundada en el miedo:

La fe religiosa y la superstición son muy diferentes. Una surge del temor y es una especie de falsa ciencia. La otra es un confiar (Wittgenstein 2003, p. 134).

El judío, continúa Weininger, es incapaz de sentir las cosas como símbolos de otras más profundas, de admirarse o avergonzarse ante los acontecimientos naturales (o ante aquello que sólo se conoce de manera vaga o confusa). Y ello solo conduce a la forma materialista de la ciencia.

El judaísmo es sentido por Weininger como aquella tendencia por la cual la ciencia queda reducida a un medio para alcanzar un fin. El conocimiento se somete aquí a fines útiles. Y es que el judío, a diferencia del ario, es incapaz de darse cuenta de que precisamente lo inescrutable (lo que no se puede medir, lo inefable) es "lo que concede su valor a la existencia" (Weininger 2004, p. 489). Para el judío, continúa Weininger, no existen verdaderos problemas y se contenta con ver el mundo de la manera más sencilla y común que le sea posible. Su labor intelectual no se encamina a resaltar de las tinieblas el eterno deber sino a "comprender", de un modo estéril o infructífero, lo que de hecho se encuentra ante él, evitando a toda costa los obstáculos espirituales que puedan presentársele 30 :

\footnotetext{
28 Aunque aquí no vamos a dilucidar en qué sentido podría entenderse que Wittgenstein es un pensador judío, Henry Abramovitch defiende que existen paralelismos significativos entre la forma literaria y el método de los textos de Wittgenstein y el Talmud y que el filósofo reúne muchos de los atributos del pensador talmúdico (Abramovitch 2006, pp. 533-553). De ser así, Chaterjee tendría razón y Wittgenstein habría ocultado conscientemente este hecho.

29 Weininger (2004), p. 488.

30 Esta reflexión vuelve a llevarnos hasta Wittgenstein, quien acusa a Ramsey de ser un pensador burgués porque la verdadera reflexión filosófica le resultaba ajena e inquietante: "no pensó sobre la esencia del Estado - o no lo hizo con gusto - sino sobre la manera de ordenar racionalmente este Estado. El pensamiento de que este Estado no es el único posible lo intranquilizaba en parte y en parte lo abu-
} 
La ciencia antifilosófica (no la afilosófica) es en el fondo judía (Weininger 2004, p. 489).

De ahí que los judíos sean los que más fácilmente han aceptado una concepción mecánico-materialista del mundo. La tendencia puramente química del arte de curar también es judaica y fueron los judíos los que introdujeron en la ciencia natural la atrevida alusión a ciertas cuestiones que el ario siempre ha considerado como pertenecientes al destino, por ejemplo, la elección y manipulación de los factores que determinan el sexo del futuro hijo.

Wittgenstein también reconoce y lamenta que el espíritu con el que trabaja hoy la ciencia sea típicamente judío y considera primitivos a los hombres civilizados que participan de tal espíritu, pues creen que el progreso de la ciencia ha permitido "superar" el asombro y el temor ante las cosas cotidianas; y suponen que era el escaso desarrollo de la ciencia lo que obligaba a los hombres primitivos a asombrarse ante ellas y temerlas. Para Wittgenstein, por el contrario, el primitivismo no se halla en el asombro ante lo cotidiano, sino en la creencia de que ese asombro es inversamente proporcional al grado de desarrollo de la ciencia y la técnica:

... Puede ser que se llame primitivo al no sorprenderse ante las cosas, pero justo entonces serían los hombres actuales y Renan mismo primitivos, si creen que la aclaración de la ciencia puede superar el asombro.

Como si el relámpago fuera ahora algo más cotidiano o menos asombroso que hace dos mil años (Wittgenstein 2003, p. 37).

Vemos aquí cómo Wittgenstein, coincidiendo con Weininger, localiza lo valioso fuera del mundo de los hechos, más allá de lo explicable por la ciencia:

Aun cuando todas las posibles cuestiones científicas hayan recibido respuesta, nuestros problemas vitales todavía no se han rozado en lo más mínimo (Wittgenstein 1997, 6.52).

Según Weininger, a los judíos, como a las mujeres, les falta profundidad, y el tipo específico de inteligencia que se les atribuye tanto a unos como a otras es la infinita capacidad de adaptación a las finalidades externas y su infinita capacidad de mutación. El espíritu judío es dúctil, maleable, y sus pensamientos carecen de raíz. Precisamente porque no es una individualidad, una mónada, porque no tiene límites precisos ni alberga en su interior una medida original del valor, porque no es nada, puede llegar a ser cualquier cosa.

rría. Quería llegar lo más rápidamente posible a reflexionar sobre las bases de este Estado. Aquí está su capacidad y su verdadero interés; en tanto que la verdadera reflexión filosófica lo intranquilizaba, hasta que podía dejar a un lado como algo trivial su resultado (cuando tenía alguno)" (Wittgenstein 2003, p. 55). 
La idea de la maleabilidad de los judíos también está presente en Wittgenstein. Recordemos:

La tragedia consiste en que el árbol no se dobla sino que se rompe, la tragedia es algo no judío... (Wittgenstein 2003, p. 32).

Hasta aquí parece que la descripción del Judío que ofrece Weinigner concuerde completamente con la de la Mujer, pero el filósofo señala una diferencia esencial: la causa de que el judío no sea nada es que no cree en nada. El judío no solo no cree en Dios, sino tampoco en el ateísmo, ni siquiera cree en sus creencias; es el "hombre incrédulo", que además considera este rasgo suyo como una particular astucia. Esto explicaría también su intolerancia, una actitud que surge siempre, no de la devoción, sino de la falta de seguridad individual en la fe. Sin embargo, no ocurre lo mismo con la Mujer:

Su semejanza se basa sobre todo en que aquellos y éstas creen poco en sí mismos. Pero las mujeres creen en los demás, en el hombre, en el niño, en el "amor"; tienen un centro de gravedad, si bien éste se encuentra fuera de ellas. El judío no cree en nada, ni en sí mismo ni en los otros; no encuentra un apoyo en los extraños, ni siquiera extiende sus raíces hacia éstos, como hace la mujer. La inestabilidad es su morada, su profunda incomprensión para los bienes inmuebles y su preferencia por el capital mueble parecen ser simbólicas (Weininger 2004, p. 500).

La incredulidad, como vemos, es para Weininger el rasgo esencial del Judío. El empirista, con su positivismo, demuestra su fe: confía en el perfeccionamiento de la ciencia exacta y en la unificación de la misma, aunque pretenda enmarcarla dentro del reino de los sentidos. Incluso el escepticismo, que con frecuencia se deriva del empirismo, requiere estar convencido de algo, al menos de que cierta seguridad en el ámbito del conocimiento teórico es imposible. Pero puesto que el Judío no cree en nada, se refugia en lo material.

El judío es, por tanto, siempre en opinión de Weininger, el hombre irreligioso e impío. Le falta la simplicidad de la fe y se caracteriza por la multiplicidad interior. Considerado como idea es:

Esta ambigüedad interna, esta carencia de realidad inmediata interior de cualquier acontecimiento psíquico, la pobreza de ese modo de existir en sí y por sí del cual fluye la fuerza creadora (Weinigner 2004, p. 504).

Weininger sostiene que el individuo judío es el que más lejos se haya de la idea de genialidad, que involucra la máxima moralidad y capacidad creadora. Al mismo tiempo, contrapone la genialidad al talento, que considera una mera destreza, una 
habilidad innata que puede entrenarse, pero que no siempre tiene relación con la genialidad, pues no siempre está al servicio del sujeto inteligible, de lo divino en el hombre, de la voluntad o del carácter.

Sabemos que Wittgenstein comparte la descripción que hace Weininger de la genialidad como determinada relación entre el talento y el carácter ${ }^{31}$, y por eso pensamos que también coincide con él cuando, por un lado, afirma que el mayor pensador judío no pasa de ser un talento y, por otro, reconoce que él mismo participa de la idea de judaísmo, pues no ha sido capaz de descubrir un movimiento intelectual y su pensamiento no es creativo, sino únicamente reproductivo 32 .

No obstante, las reflexiones wittgensteinianas con respecto al judaísmo siempre son menos apasionadas y más críticas que las de Weininger. Por ejemplo, Wittgenstein sostiene que la capacidad reproductiva de los judíos no debe ser considerada por sí misma un vicio. El peligro aparece cuando uno confunde su labor reproductiva con la propiamente creativa:

Podría decirse (sea correcto o no) que el espíritu judío no es capaz de crear ni una hierbecilla ni una pequeña flor, pero que su índole es copiar la hierba o la flor que han crecido en otro espíritu y producir así una imagen limpia. Esto no es la mención de un vicio y todo está en orden mientras quede completamente claro. Sólo se vuelve peligroso cuando se confunde la manera de la obra judía con la de la no judía y en especial cuando lo hace el creador de la primera, lo que es muy natural. (¿Acaso no parece tan orgulloso como si él mismo hubiera sido ordeñado?). Es típico del espíritu judío entender mejor la obra de otro que él mismo (Wittgenstein 2003, p. 58).

A continuación Wittgenstein confiesa que él mismo confunde frecuentemente su propia labor reproductiva con la creativa.

Si Chaterjee tiene razón, que Wittgenstein caracterice la labor del judío como reproductiva y entienda que la creación es ajena al espíritu judío se explica por el conocimiento que tenía de la postura tradicional judía. De acuerdo con ella la mente judía dedica todo su esfuerzo al comentario, la clarificación y el análisis de los textos bíblicos, que no son creación propia; se abstiene de escribir libros o, dicho de otro modo, todo lo que escribe es una interpretación del único libro. Más aún, toda la base del movimiento rabínico descansa en la interpretación: las instituciones políticas, jurídicas, religiosas, la justificación de su historia y su destino, su esperanza en el futuro, su sistema de valores, etc., son un efecto de la interpretación 33 .

\footnotetext{
31 Ver Calabuig (2007a).

32 Ver Wittgenstein (2003), p. 57.

33 Chaterjee (2005), pp. 56,57.
} 


\section{El fundador de religiones}

Pese a su valoración negativa del judaísmo, Weininger sostiene que esa idea encierra dentro de sí la única esperanza para el ser humano. Esta tesis se sigue, como veremos, de su caracterización del fundador de religiones:

El fundador de religiones es el hombre que ha vivido sin Dios, y luego se siente penetrado por la máxima fe (Weininger 2004, p. 509).

Es el individuo con menores seguridades; en él todo está amenazado y en peligro, y todo - no esto o aquello - debe conquistarlo en su vida con su propio esfuerzo (Weininger 2004, p. 510).

El fundador de religiones es el individuo más genial, pues es el que ha logrado superarse en mayor grado (Weininger 2004, p. 511).

Si en los genios típicos se da desde el nacimiento cierta tendencia hacia el bien, si estos nacen ya con parte del camino hacia la divinidad recorrido, los hombres que han fundado las grandes religiones de la humanidad han tenido que recorrer por ellos mismos el camino completo, sin ayuda externa y sin ventaja.

Ese camino es la más profunda y completa transformación que puede darse en el hombre. Pues es un proceso en el que se aniquila el antiguo ser, el malo, y se coloca en su lugar el bueno, que ha de ser creado. Dicho de otro modo, lo que significa es la creación del ser a partir de la nada. Y esto es propiamente lo que Weininger considera el milagro. Por otro lado, lo que fundamenta nuestra creencia en el milagro es que este es sentido como un deber.

El fundador de religiones es, por tanto, el que ha cometido íntegramente el pecado original y ahora tiene que expiarlo completamente. El que lo ha problematizado todo y debe también por ello dar respuesta a todo, liberándose así del universo, de las leyes naturales, de la necesidad, divinizando al hombre y humanizando también a Dios.

Para Weininger, Buda y Cristo son dos ejemplos de esta transformación, pues estuvieron sometidos a tentaciones mucho más fuertes que el resto de los hombres. También Sócrates tuvo que librar su particular batalla contra el mal (cuando estuvo en Potidea).

Pues bien, el judaísmo y el cristianismo son las dos opciones más opuestas e inconmensurables por las que pueda optar el alma humana. Tanto es así que al Judío le resulta incomprensible la figura y la doctrina de Jesús.

Cristo es para Weininger el hombre que ha vencido en sí mismo la negación más fuerte, el judaísmo, para crear la posición más fuerte, el cristianismo. El pecado original de Cristo era, por tanto, el judaísmo. Al vencer al enemigo más poderoso se colocó por encima de los otros fundadores de religiones. De ahí que el nacimiento de Cristo en Palestina no pueda atribuirse a una circunstancia fortuita. 
No pretendemos sostener aquí que Wittgenstein comparta la concepción weiningeriana del fundador de religiones, pero lo cierto es establece cierta conexión entre el judaísmo y la santidad. Recordemos:

El «genio» judío es solo un santo. El mayor pensador judío es solo un talento. (Yo, por ejemplo) (Wittgenstein 2003, p. 57).

La afirmación de que "el «genio» judío es sólo un santo" no solo está en sintonía con la concepción weiningeriana de la genialidad y el judaísmo, según la cual el judío no puede ser un genio - lo que se manifiesta en el hecho de que la palabra «genio» aparezca entre corchetes -, sino que también tiene en cuenta las afirmaciones de Weininger sobre el fundador de religiones, tal y como sugiere la referencia a la santidad.

Una vez más, Chaterjee interpreta esta sentencia desde los parámetros del judaísmo tradicional. Piensa que Wittgenstein está usando las palabras "genio" y "talento" siguiendo los peculiares estándares del mundo judío. Desde esa perspectiva, el único genio concebible es el hombre santo o el profeta, el que trajo la palabra de Dios a Israel y todos los demás pensadores judíos seculares no son reconocidos más que como talentos.

Chaterjee piensa que la última frase, en la que Wittgenstein se reconoce a sí mismo como un pensador judío con talento, es una clara refutación de la postura weiningeriana. Wittgenstein le estaría diciendo a Weininger, algo inmodestamente, que sí que hay pensadores judíos grandes o geniales (por ejemplo, él mismo), pero que se trata de un tipo de genialidad que la sensibilidad platónico cristiana no reconocería ni aunque la tuviera delante de las narices. La "genialidad" judía consistiría en entenderse a uno mismo y a los demás incluso mejor de lo que ellos se entienden:

Es típico del espíritu judío entender mejor la obra de otro que él mismo (Wittgenstein 2003, p.58)

Pero, aunque la interpretación de Chaterjee es sugerente, esta no explica por qué en la primera frase ("el «genio» judío es solo un santo") la santidad aparece como algo imperfecto, ya que Weininger la considera el tipo más elevado de genialidad.

Es posible que Wittgenstein tuviera en mente la idea de santo que aparece en Las variedades de la experiencia religiosa de William James ${ }^{34}$. Para James una de las más valiosas virtudes del santo consiste en su capacidad para prescindir de todo lo que antes le proporcionó seguridad y, más en concreto, en su capacidad para la pobreza voluntaria, pues está convencido de que "el temor a la pobreza que preva-

34 Ver Sanfélix (2007). 
lece en las clases cultas es la enfermedad moral más grave que padece nuestra civilización"35.

En ese sentido, para Wittgenstein la pobreza voluntaria constituiría uno de los sacrificios más importantes y dolorosos para el judío; pues considera, como hemos visto, que uno de los rasgos típicos del judío es que le gusta ser rico. El hecho de que Wittgenstein renunciara a su herencia en favor de su familia puede leerse como un esfuerzo por aproximarse al ideal moral de la santidad. Y es que, a partir de sus Diarios secretos y otras observaciones dispersas, puede deducirse que Wittgenstein, quien reconoce en sí mismo ciertos rasgos judíos (y femeninos), aspiraba a la santidad y la sentía como un deber ${ }^{36}$.

Algo importante, donde puede que radique la diferencia entre el santo al que se refiere Wittgenstein y el fundador de religiones de Weininger, es que para James "los santos serán normalmente leales a los ídolos temporales de la institución" 37. No son, por tanto, el origen de una nueva manera de ver las cosas. Es posible que Wittgenstein estuviera usando aquí la terminología de James y tal vez por eso dice que el "genio" judío es solo un santo, porque no es creativo. Si esto es así, podría decirse que para Wittgenstein el talento es a la genialidad lo que la santidad es al fundador de religiones. Es decir, que ni el talento (que no sería más que una habilidad) ni la santidad (que consistiría sobre todo en obediencia), atribuibles al judío, serían dones creativos.

Siendo más duro que Weininger con la caracterización del judaísmo (o usando la terminología weiningeriana de un modo más coherente), Wittgenstein estaría afirmando que tanto el genio como el fundador de religiones son ajenos al espíritu judío, que es incapaz de crear. Y ambas posibilidades le estarían negadas al individuo que participa de ese espíritu. Pero lo cierto es que aquí nos movemos en un terreno especulativo.

En definitiva, ambas interpretaciones coinciden en que Wittgenstein acepta la premisa weiningeriana de que el concepto de genialidad no es aplicable al judío. La razón de ello parece ser que esa idea, construida por la cultura occidental para enaltecer al individuo que reúne los rasgos más valorados por la propia cultura, no incluye las características típicas del judío, aquellas que la tradición judía fomenta y valora. No obstante, desde la perspectiva crítica wittgensteiniana, no habría razones objetivas, externas a cualquier contexto cultural, que justificaran el menosprecio de esas características.

Weininger se basa en los arquetipos de Mujer y de Judío para desarrollar su crítica a la civilización. Sostiene que el espíritu moderno, considerado desde cualquier perspectiva, es judaico y afeminado. Ello se manifiesta, por ejemplo, en el arte, que

\footnotetext{
35 James (1902), p. 278.

36 Para más información sobre esta cuestión ver Sanfélix (2007).

37 James (1902), p. 279.
} 
es sólo un envoltorio o decoración; en la ciencia, que se identifica con la economía y con la técnica; en la política, por su incomprensión para la idea de Estado y su tendencia al anarquismo, al capitalismo y al comunismo; y en la ética, porque esta encuentra su referencia en la especie y no en el individuo. Por todo ello:

La humanidad espera al nuevo fundador de religiones, y la lucha busca la decisión como en el año uno. La humanidad tiene de nuevo la elección entre el judaísmo y el cristianismo, entre la especie y la personalidad, entre la nada y la divinidad. He aquí los dos polos; entre ellos no existe un tercer reino (Weininger 2004, p. 515).

De todo esto se extrae una paradójica conclusión: el judaísmo tiene que existir para ser superado. La crisis espiritual del judío es para Weininger la fuente de conocimiento esencial; y la existencia del individuo judío, la última esperanza del mundo.

Aunque las siguientes observaciones de Wittgenstein no guardan una conexión clara con la idea del judío irreligioso cuya posibilidad de transformación constituye una esperanza para el mundo, lo cierto es que son compatibles con ella:

El judío es un paraje desierto bajo cuyas delgadas capas rocosas se encuentran las masas ardientes y fluidas de lo espiritual.

La religión como locura es locura salida de la irreligiosidad (Wittgenstein 2003, p. 49).

\section{Conclusión}

Lo interesante de la obra de Weininger, si reside en algún lugar, ha de ser en la caracterización que hace de los valores convencionales del conformismo y la mediocridad. El tipo conformista sería esclavo de una construcción social particular de la idea de sexualidad; y sería su "minoría de edad", o su incapacidad para legislar sobre su propio comportamiento, lo que le permitiría adaptarse al entorno. De ahí que su actitud frente a las cosas de la vida sea externa, irreflexiva y mecánica.

Aunque no oculta su antijudaísmo, Weininger deja claro que no pretende con su análisis "justificar ninguna persecución teórica o práctica contra los semitas", pues sería contraproducente e inmoral. Además, en su obra puede rastrearse un profundo respeto, incluso veneración, de la idea de humanidad: Weininger apela a un ideal humano, al dios que hay en el hombre, y no a otras consideraciones de raza o nación ${ }^{38}$. Pide para las mujeres (y para todo individuo con tendencias femeniles, como los judíos) que se les permita progresar espiritualmente hasta convertirse en "auténticos seres humanos"; y asegura que el requisito para que esto ocurra es que

38 Ver Weininger (2004), p. 266. 
sean tratadas como iguales. Según Steven Beller, este alegato colocaría a Weininger lejos del irracionalismo y enfrentado a la política antiliberal del antisemitismo de su época 39 .

Como hemos visto, aunque Wittgenstein está de acuerdo en lo fundamental con la descripción que ofrece Weininger del judaísmo, e incluso siente cierta animadversión hacia el espíritu judío (como refleja su autocrítica), considera injustificados o carentes de fundamento los juicios de valor sostenidos por este. Dicho de otro modo, fiel a su relativismo ético, Wittgenstein considera imposible justificar filosóficamente la inferioridad del espíritu judio, que es precisamente lo que Weininger pretende, pero comparte, sin embargo, la caracterización que este ofrece del mismo. Admite, por ejemplo, que al judío le interesa más el dinero que la propiedad, que la persecución ejercida sobre el pueblo judío no explica su especial habilidad para ocultarse, que el espíritu con el que trabaja la ciencia de su época (recordemos que es antimoral) es típicamente judío y, lo más importante, que el mayor pensador judío no pasa de ser un talento. Le niega, por tanto, la creatividad y la genialidad.

Wittgenstein usa la idea winingeriana de judaísmo para entender mejor la obra de otros autores, su época e incluso a sí mismo, lo que, como hemos visto, también es un rasgo weiningeriano. Y es que a juicio de Wittgenstein, Weininger estaría libre de un error muy común: considerar la historia de los judíos como una anomalía y consecuentemente menospreciar su influencia en la historia de los pueblo europeos.

\section{Referencias bibliográficas}

Abrahamsen, D. (1946): The Mind and Death of a Genius, New York, Columbia University Press.

ABRAmovitch, H. (2006): "The Jewish Heritage of Ludwig Wittgenstein: Its influence on His Life and Work", Transcultural Psychiatry, December, pp. 533-553.

Calabuig, N. (2007a): "Weininger y Wittgenstein sobre el genio y el talento." En Sánchez, N. (Ed.). Cultura y civilización. En torno a Wittgenstein, Pre-textos, Valencia, pp. 137-157.

Calabuig, N. (2007b), "La expresión de lo humano en el arte: Adolf Loos y la Viena de Fin-de-Siècle", Thémata. Revista de Filosofía no 39, pp. 410 - 415.

Calabuig, N. (2010a), "Los ecos de la sonata a Kreutzer. Tolstoi, Weininger y Wittgenstein.” Perona J. (Ed.), En Wittgenstein y la tradición clásica. Los peldaños de una escalera, Valencia, Pre-textos.

\footnotetext{
39 En Harrowitz y Hyams (1995), pp. 91-103, Steven Beller defiende la tesis de que Weininger pertenece a una corriente de pensamiento que podría denominarse liberalismo intolerante.
} 
Calabuig, N. (2010b), “God's Will as Man's Command: Weininger, Wittgenstein and the Divine". \ókoৎ Revista Filosófica, Madrid-México, Plaza y Valdés editores, Vols. 5-6, pp. 31-63.

Beller, S. (1995): “Otto Weininger as Liberal?" en Harrowitz, N. y Hyams B. (ed.), Jews and Gender. Responses to Otto Weininger, Philadelphia. Temple University Press, pp. 91-102.

Chatterjee, R. (2005): Wittgenstein and Judaism. A Triunph of Concealment, New York, Peter Lang Publishing.

Dallago, C. (1912): Otto Weininger und sein Werk, Innsbruck, Brenner- Verlag.

Harrowitz, N. A. y Hyams B. (1995): Jews and Gender. Responses to Otto Weininger, Philadelphia, Temple University Press.

JANIK, A. (2004): "Weininger and the Two Wittgensteins" en Wittgenstein Reads Weininger. Cabridge, Cambridge University Press, pp. 62-89.

JANIK, A. (1985): Essays on Wittgenstein and Weininger, Amsterdam, Rodopi.

JANIK, A. y Toulmin, S. (1998): La Viena de Wittgenstein, Madrid, Taurus.

Klagge, J. C. (Ed.), Wittgenstein: Biography and Philosophy (pp.221-236). Cambridge: Cambridge University Press.

Luft, D. S. (2003): Eros and Inwardness in Viena. Weininger, Musil, Doderer. Chicago and London, The University of Chicago Press.

MCGuinNess, B. (1991): Wittgenstein: El joven Ludwig (1889-1921), Madrid, Alianza Editorial S. A.

McGuinness, B. (2001): "Wittgenstein and the idea of Jewishness". En J. C., Klagge (ed.), Wittgenstein: Biography and Philosophy (pp.221-236). Cambridge, Cambridge University Press.

Monk, R. (2002): Ludwig Wittgenstein, Barcelona, Anagrama.

Rhees, R. (1989): Recuerdos de Wittgenstein. México, Fondo de Cultura Económica.

SANFÉLIX, V. (2007): "Un alma enferma. La experiencia religiosa de Wittgenstein a la luz de Las variedades de la experiencia religiosa de William James", Revista de filosofía Dianoia, V. 52, n 59, México.

Sengoopta, Ch. (2000): Otto Weininger. Sex, Science, and Self in Imperial Vienna, Chicago, The University of Chicago Press.

Stern, D. (2001): "Was Wittgenstein a Jew?", en Klagge J. C., Wittgenstein. Biography and Philosophy, Cambridge, Cambridge University Press, pp. 237272.

SzaBADOS, B. (2004): "Eggshells or Nourishing Yolk? A Portrait of Wittgenstein as a Weiningerian", en Wittgenstein Reads Weininger, Cambridge, Cambridge University Press, pp. 29-61.

Weininger, O. (2000-2009): Collected Aphorisms, Notebook and Letters to a Friend. Traducción y Edición de Kevin Solway \& Martin Dudaniec. 
Weininger O. (2004): Sexo y Carácter. Madrid, Losada.

WeIninger O. (2008): Sobre las últimas cosas. Madrid, Mínimo Tránsito.

Wittgenstein, L. (1997), Tractatus logico-philosophicus. Alianza Editorial, Madrid.

Wittgenstein, L. (1982): Von Wright G.H y Anscombe G. E. M. (Ed.), Diario filosófico (1914-1916). Barcelona, Editorial Ariel S.A.

Wittgenstein, L. (2003): Aforismos. Cultura y Valor, Madrid, Austral.

Wittgenstein, L. (1989): Conferencia sobre ética, Barcelona, Paidós Ibérica, S. A. WitTGenstein, L. (1992): Lecciones y conversaciones sobre estética, psicología y creencia religiosa, Barcelona, Ediciones Paidós. I.C.E de la Universidad Autónoma de Barcelona.

WitTGENSTEIn, L. (1997a): Ocasiones filosóficas 1912-1951, Madrid, Cátedra.

Wittgenstein, L. (1997b): Cartas a Russell, Keynes y Moore, Madrid, Editorial Taurus.

Wittgenstein, L. (1991): (Baum W. Edt.), Diarios secretos 1914-1916, Madrid, Alianza editorial.

Wittgenstein, L. y Bouwsma, O. K. (2004), Últimas conversaciones, Salamanca, Sígueme.

Noemí Calabuig Cañestro

Facultad de Filosofía y Ciencias de la Educación

Universidad de Valencia

noemi.calabuig@uv.es 